\title{
Evaluation of coping with chronic rheumatic disease, in the context of socio-demographic factors and disease duration, based on the example of patients with ankylosing spondylitis
}

\author{
Anna Piekutin ${ }^{1}$, Matylda Sierakowska², Halina Doroszkiewicz ${ }^{3}$, Elżbieta Krajewska-Kułak ${ }^{2}$ \\ ${ }^{1}$ Department of Anaesthesiology and Intensive Care, Medical University of Białystok, Poland \\ ${ }^{2}$ Department of Integrated Medical Care, Medical University of Białystok, Poland \\ ${ }^{3}$ Department of Geriatrics, Medical University of Białystok, Poland
}

\begin{abstract}
Objectives: Ankylosing spondylitis (AS) impairs patients' functioning, reducing their quality of life. The author of salutogenesis, Antonovsky, claims that maintaining an inner balance in a chronic disease is possible through a high sense of coherence. The aim of the current study was to identify socio-demographic factors and disease duration related to the feeling of coherence of patients with AS, acceptance of disease and risk of depression.

Material and methods: The study was conducted on 82 patients with diagnosed AS. The research method was a diagnostic survey using the Life Orientation Questionnaire (SOC-29), Beck Depression Inventory (BDI) and Acceptance of Illness Scale (AIS).

Results: In the study, the majority of the patients were male (89\%), aged $42( \pm 11.3)$. The average duration of AS is $13( \pm 7.8)$ years. It was reported that with age, illness acceptance got worse $\left(r_{p}=\right.$ $-0.567, p<0.0001)$, and the risk of depressive disorders increased $\left(r_{p}=0.648, p<0.0001\right)$. The longer the patient suffered from AS, the weaker was their illness acceptance $\left(r_{p}=-0.446, p<0.0001\right)$ and sense of coherence $\left(r_{p}=-0.448, p<0.001\right)$ whereas the risk of depressive disorder increased $\left(r_{p}=0.479, p<0.0001\right)$. A high linear correlation between illness acceptance and sense of coherence $\left(r_{p}=0.638, p<0.0001\right)$ and a very high negative correlation between overall sense of coherence and risk of depression $\left(r_{p}=-0.857, p<0.0001\right)$ were observed.

Conclusions: Patients with low sense of coherence demonstrated poorer adaptation to the illness and a greater risk of depressive disorders. Factors lowering the sense of coherence and illness acceptance and increasing risk of depression in the studied patients with AS were progressing illness, older age and lower education level.
\end{abstract}

Key words: ankylosing spondylitis, sense of coherence, illness acceptance, risk of depression.

\section{Introduction}

Rheumatic diseases determine the patients' lifestyle. The course of the disorders is usually chronic and progressive. Pain constantly accompanies the patient in almost all the diseases, disability in everyday life increases, and a high dependence on the help of people from the immediate surroundings occurs. Rheumatic diseases are a tremendous emotional burden for both the patient and his or her family. This is due not only to the difficulties caused by chronic connective tissue diseases, but by the unpredictability of the course of the disease [1, 2].

Ankylosing spondylitis (AS) is a chronic progressive systemic disease of unknown etiology. It is one of the most common seronegative inflammatory spondyloarthropathies (SpA). The mean prevalence of AS per 10,000 is estimated at 23.8 in Europe (1.30 to 1.56 mil-

\footnotetext{
Address for correspondence:

Matylda Sierakowska, Department of Integrated Medical Care, Medical University of Białystok, 7A Marii Skłodowskiej-Curie St., 15-096 Białystok, Poland, e-mail: matyldasierakowska@gmail.com
}

Submitted: 16.10.2018; Accepted: 30.11.2018 
lion) [3]. In Poland, almost 150,000 people suffer from AS [4]. Prevalence is generally higher among men, with rate estimates ranging from 1.2 to seven times higher than in females. The disease usually begins at the end of adolescence or in young adulthood (between 17 and 35 years) $[3,4]$.

The inflammatory process in AS mainly involves sacroiliac joints, spine joints and tendinous attachments. Swelling, pain and stiffness of joints lead to limitation of mobility and total or partial stiffening of the joints (mainly spine) affected by the disease [4]. Restricting the movement of the spine makes it difficult to perform various activities, such as lifting objects from the floor, moving, reaching for a shelf, driving a car, as well as everyday activities, such as getting up from a chair or from the floor and putting on socks. The disease is often accompanied by fatigue, which is the result of chronic inflammation and sleep problems [5].

The progressive course of AS is also associated with the risk of depression regardless of patients' gender, resulting from the lack of effective therapy, anxiety and adaptive disorders associated with adaptation to new life changes or loss of work following progressive disability and disease absence $[2,6]$. The problem of the lack of acceptance of the disease and the risk of depressive disorders is also connected with the fact that AS starts at an early age (at the end of adolescence or young adulthood). The development of the disease is usually imperceptible and the symptoms grow gradually. Since the beginning of AS is difficult to grasp, the diagnosis is often late, when there is already permanent, destructive damage within the osteo-articular system (osteogenesis), limiting patients' mobility and daily functioning [4-6].

Life with a chronic disease is often associated with the need for the patient to redefine their abilities. To a large extent it depends on the patient's inner resources that enable them to deal with a difficult situation.

According to Antonovsky's theory of salutogenesis, specific behaviors, development and recovery are dependent on generalized immune resources, stressors, sense of coherence and lifestyle [7]. The sense of coherence (SOC) is a global orientation of a person that stems from the extent to which he/she possesses a stable, dynamic sense of certainty, that the environmental stimuli are structured, predictable, and explainable [7, 8]. The sense of coherence is an internal and central factor that causes a person to cope with stress, be healthy or recover quickly. It consists of three components:

- sense of comprehensibility (the person perceives the incoming information as ordered, consistent, understandable),
- sense of manageability (the person perceives available resources as sufficient to meet his/her needs and is convinced that the difficulties can be overcome),

- sense of meaningfulness (the person has a sense of meaning in life, willingness to make efforts and commitment to deal with problems).

According to Dobrucka-Janeczek and Jędryka-Góral [1] accepting and adapting to a new situation caused by illness is not easy, as it requires the patients to know their own possibilities and limitations. Antonovsky demonstrates that maintaining an inner balance in a chronic disease is possible through a high sense of coherence, which affects taking and maintaining prohealth actions. The general sense of coherence in the functional sense motivates the patient to act and cope with new challenges. It also helps in managing the use of their abilities $[9,10]$.

The evaluation of the adaptability of AS patients enables an effective way of dealing with chronic rheumatic disease. Studies show that the complexity of problems of the patient with AS entails the need for taking them under comprehensive care, which can be ensured by a team of health professionals. The task of the interdisciplinary team is cooperation for the benefit of the patient as well as individual therapeutic procedures [11].

The study of AS patients, mainly men with chronic rheumatic disease, with the application of SOC to estimate the potential for coping with the illness, is important for finding targeted and effective methods of comprehensive therapeutic interventions.

\section{Research hypothesis}

The following research hypotheses were adopted in the study:

- Patients with AS, due to the somatic ailments and progressive disability influencing their performance of social roles, have difficulties with coping with the disease, and manifest a lack of its acceptance.

- Adequate recognition and understanding of the cognitive and emotional resources of the patient, their ability to perceive their situation and motivation for action can contribute to a better and more effective health professionals' impact on the patient in the overall therapeutic process.

In order to verify the assumptions of the above hypotheses, the following research objectives were formulated:

- Assessment of the adaptability of the patients with AS (SOC) for optimal coping with illness.

- Assessment of the relationship between the sense of inner balance (coherence) and the level of illness acceptance and risk of depression. 
- Identification of socio-demographic factors, clinical form of AS and illness duration, which might be linked to the SOC, illness acceptance (AIS), and risk of depression $(\mathrm{BDI})$ in patients with AS.

\section{Material and methods \\ Participants and procedures}

The study was conducted on 82 patients with diagnosed AS during hospitalization of patients in the Department of Rheumatology and Internal Diseases of the Medical University of Białystok in the period from September 2015 to April 2016. The criteria for inclusion in the study were AS diagnosis based on the Assessment in Ankylosing Spondylitis (ASAS) for SpA and modified New York criteria [3, 4]. Patients who met the ASAS criteria were qualified for the study according to the order of their admission to the Department of Rheumatology. All patients hospitalized within the above-mentioned period agreed to participate in the study. There was 100\% return of the completed questionnaires during hospitalization.

\section{Ethics approval}

The research conforms with the Good Clinical Practice guidelines and the procedures followed were in accordance with the Helsinki Declaration of 1975, as revised in 2000 (concerning the ethical principles for the medical community and forbidding releasing the name of the patients, their initials or the hospital evidence number) and with the ethical standards of the institutional committee on human experimentation (statute from the Bioethics Committee of the Medical University in Białystok, Poland no. R-I-002/529/2015. Members of the research team gave written and verbal information about the study to potential participants. The participants were informed about the project and gave written consent to participate. The patients filled in the questionnaires themselves.

\section{Study instrument}

The research technique was a diagnostic survey using the Life Orientation Questionnaire (SOC-29) by Antonovsky [7], the Beck Depression Inventory (BDI) by Beck [12] and the Acceptance of Illness Scale (AIS) [13], adapted by Juczyński [14].

The SOC-29 questionnaire allows for assessing the individual level of sense of coherence and its 3 components - comprehensibility (11-71), manageability (17-70), and meaningfulness (12-56). The general SOC-29 score is in the range of 29-203 points; the higher the score, the stronger the sense of coherence $[15,16]$. The Polish version of the SOC-29 was developed in 1993. The evaluation showed very high psychometric reliability of the tool (Cronbach's $\alpha=0.78)[10,17]$.

The BDI (0-56) serves as a preliminary assessment of the risk/severity of depression. It contains 21 groups of statements. The patients themselves assess the intensity of occurrence of particular depressive symptoms during the last 24 hours. It is an auxiliary screening tool which cannot replace the clinical psychiatric examination needed to diagnose depression. The following point ranges were taken into account in the score assessment: lack of depression or low mood: 0-10, moderate depression: 11-27, severe depression: 28 or more $[18,19]$. Standardization of Poland: Cronbach's $\alpha=0.93$ and 0.95 [20, 21].

The AIS consists of 8 statements describing the negative consequences of ill health (recognition of the limitations imposed by the disease, lack of self-sufficiency, sense of dependence on others, reduced self-esteem). The score is the sum of all statements (8-40); the higher the score, the better the illness acceptance. The psychometric properties of AIS have been estimated from patients with chronic pain. The accuracy of the Polish version of the scale (Cronbach's $\alpha=0.85$ ) is similar to the reliability of the original version (Cronbach's $\alpha=0.82$ ) $[13,14]$. The patients filled in the questionnaires themselves.

\section{Data analysis}

All data were analyzed using PQStat v.1.4.2 software. We tested the null hypothesis of no correlation between sense of coherence, acceptance of disease and risk of depression. Pearson's $\left(r_{p}\right)$ correlation coefficient is reported together with $p$-values, with $r$ of $0.10,0.20$ and 0.50 representing small, medium and large effects respectively. The effects of gender, age and disease duration were tested across all measures. One-way ANOVA was used to assess for differences across age groups, disease duration, occupational status, place of residence and educational background. The level of significance $\alpha=0.05$.

\section{Results}

\section{General characteristics of the study group of patients with ankylosing spondylitis}

In the study, involving 82 patients, the majority were male (89\%). As indicated by data in Table I, the mean age of patients was 42 years. Considering the civil status variable, the vast majority of respondents were married (63.4\%). The respondents lived mainly in the city (76.8\%) and had higher education (41.5\%) and secondary education $(31.7 \%)$. Analyzing the distribution of variables re- 
lated to occupational status, the most numerous group consisted of professionally active people (73.2\%).

The axial form of AS (76.8\%) was predominant among the respondents. The analysis showed that 100\% of men suffered from it. The average disease duration is 13 years (Table I).

The majority of patients who participated in the survey $(74.4 \%)$ did not report other comorbidities. The most distressing symptoms reported by the patients were pain in the lumbosacral area (75.6\%), fatigue (75.6\%) and restricted spine mobility (68.3\%). Subsequently, stiffness of the joints during the day (47.6\%) and swelling of the joints (36.6\%) were reported.

In the present study, AIS was used to assess the impact of restrictions imposed by the disease and adaptability. The overall AIS value was 26.9, which corresponds to the average level of illness acceptance (Table I).

The BDI was used to assess the risk of depression. The data in Table I identify that respondents obtained a mean BDI score of 16.8 , which may suggest a risk of moderate depressive disorder in the study population. Detailed analysis indicated that problems in the emotional sphere concerned as many as $57.3 \%$ of the studied patients, including $30.5 \%$ with a moderate degree and $26.8 \%$ with a severe degree.

Examining the level of coherence, the SOC-29 was used. The results of the study showed that patients with AS are people with an average level of sense of coherence (127). The SOC component sense of comprehensibility was on average 46.7, sense of manageability 45.4, and sense of meaningfulness 35.4. In general, it can be stated that the respondents were characterized by an average level of sense of comprehensibility, manageability and meaningfulness (Table I).

\section{Relation between age, illness duration and illness acceptance, risk of depression and sense of coherence in patients with ankylosing spondylitis}

Evaluation of the relations between socio-demographic variables studied and adaptation to disease, risk of depression and coherence identified that both the place of residence and marital status of the respondents did not have any significant relation in the evaluation of the studied variables. Nevertheless, a relation between higher education and higher values of AIS (32.4), BDI (6.4) and SOC (155.2) was demonstrated $(p<0.0001)$. The occupational status of a retired person caused worse illness acceptance (20.6) $(p=0.004)$ and an increased risk of depression (26.9) ( $p=0.003)$.

Data presented in Table II indicate that older age of the respondents had a significant relationship with lower illness acceptance, increased risk of depression
Table I. General characteristics of the study group of patients with ankylosing spondylitis

\begin{tabular}{|c|c|c|}
\hline $\begin{array}{l}\text { Variables studied } \\
\text { (score range) }\end{array}$ & $\begin{array}{c}\text { Number of } \\
\text { cases (\%) } \\
N=82\end{array}$ & $\begin{array}{c}\text { Value } \\
\text { mean }( \pm S D)\end{array}$ \\
\hline Age & & $42.0( \pm 11.3)$ \\
\hline$\leq 35$ years & $28(34.1)$ & \\
\hline $36-55$ years & $43(52.4)$ & \\
\hline$>55$ years & $11(13.4)$ & \\
\hline \multicolumn{3}{|l|}{ Gender } \\
\hline Female & $9(11)$ & \\
\hline Male & $73(89)$ & \\
\hline \multicolumn{3}{|l|}{ Civil status } \\
\hline Married & $52(63.4)$ & \\
\hline Single/widowed & $30(36.6)$ & \\
\hline \multicolumn{3}{|l|}{ Place of residence } \\
\hline City & $63(76.8)$ & \\
\hline Country & $19(23.2)$ & \\
\hline \multicolumn{3}{|l|}{ Education } \\
\hline $\begin{array}{l}\text { Elementary/vocational } \\
\text { training }\end{array}$ & $22(26.8)$ & \\
\hline Secondary & $26(31.7)$ & \\
\hline Higher & $34(41.5)$ & \\
\hline \multicolumn{3}{|l|}{ Occupational status } \\
\hline Employed & $60(73.2)$ & \\
\hline Pensioner & $13(15.9)$ & \\
\hline Unemployed/student & $9(11)$ & \\
\hline \multicolumn{3}{|l|}{ Clinical form of AS } \\
\hline Axial & $63(76.8)$ & \\
\hline Peripheral & $19(23.52)$ & \\
\hline Duration of disease & & $13( \pm 7.8)$ \\
\hline$\leq 10$ years & $33(22)$ & \\
\hline $11-20$ years & $35(23.3)$ & \\
\hline$>20$ years & $82(54.7)$ & \\
\hline AIS (8-40) & & $26.9( \pm 9.2)$ \\
\hline BDI (0-56) & & $16.8( \pm 15.3)$ \\
\hline $\begin{array}{l}\text { Lack of depression or low } \\
\text { mood }(0-10)\end{array}$ & $35(42.7)$ & \\
\hline Moderate depression (11-27) & $25(30.5)$ & \\
\hline Severe depression $(\geq 28)$ & $22(26.8)$ & \\
\hline SOC (29-203) & & $127.5( \pm 37.9)$ \\
\hline \multicolumn{3}{|l|}{ Components of SOC } \\
\hline Comprehensibility (11-71) & & $46.7( \pm 14.1)$ \\
\hline Manageability (17-70) & & $45.4( \pm 13.4)$ \\
\hline Meaningfulness (12-56) & & $35.4( \pm 11.7)$ \\
\hline
\end{tabular}

AS - ankylosing spondylitis; AIS - Acceptance of Illness Scale; BDI - Beck Depression Inventory; SOC - Sense of Coherence. 
and worse sense of adaptation (coherence). This was observed in all studied variables $(p<0.0001)$.

Moreover, with the disease duration, the studied parameters were significantly lower (AIS, SOC) and lower (BDI), indicating that patients who suffered from the disease more than 20 years had bigger problems with illness acceptance $(p=0.0001)$, were at risk of depression ( $p=0.0003$ ), and demonstrated more difficulties in maintaining inner balance (sense of coherence) ( $p=0.0009)$ (Table III).

Studies have reported that the clinical form of AS (axial, peripheral) had no significant connection with the studied variables.

The results of the statistical analyses using Pearson's correlation coefficient $(r)$ demonstrated, as indicated in Table IV, that the age of respondents and illness duration were significantly correlated with the degree of illness acceptance $(p<0.0001)$. Younger patients showed better adaptation to the disease and its acceptance than the elderly $\left(r_{p}=-0.567\right)$. Examining the illness duration variable, it was identified that the longer the patient suffered from AS, the weaker was their illness acceptance $\left(r_{p}=-0.446\right)$.

Referring to BDI scores assessing the risk of depression in patients with AS, it was observed that the age and AS duration variables were significantly correlated with the risk of depression $(p<0.0001)$. With age, the risk of depressive disorders was greater $\left(r_{p}=0.648\right)$. Additionally, prolonged duration of the disease was condu- cive to the manifestation of this type of mental disorder $\left(r_{p}=0.479\right)$ (Table IV).

The analysis of the relationship between the level of illness acceptance and the risk of depression showed that patients with a risk of severe depression reported poor illness acceptance (AIS 18.9) (Table V). There was also a high negative linear correlation $\left(r_{p}=-0.634\right)$, indicating that the higher the sense of independence and self-worth was (acceptance of arthritis), the lower was the risk of depression (Table IV).

Results of the study indicate, similarly to the analyses of illness acceptance (AIS) and the risk of depression (BDI), that elderly age of patients $(p<0.0001)$ and longer illness duration $(p=0.0009$ ) had a relationship with lower sense of inner balance (coherence - SOC-29) of patients with AS (data in Table II, III).

This is confirmed by the Pearson's correlation analysis, indicating that age was an important determinant of the overall sense of coherence $\left(r_{p}=-0.663\right)$ as well as its individual components $(p<0.0001)$. Younger respondents showed better perception of reality, belief in coping with new situations, difficulties, and problem-solving efforts compared to the older patients (data in Table IV).

When examining the illness duration variable, it was also found that the longer the patient suffered from the illness, the weaker was their sense of coherence $\left(r_{p}=-0.448\right)$, comprehensibility $\left(r_{p}=-0.453\right)$, manageability $\left(r_{p}=-0.396\right)$ and meaningfulness $\left(r_{p}=-0.452\right)$ $(p<0.0001)$.

Table II. Relationship between age, illness acceptance, risk of depression and sense of coherence of patients with ankylosing spondylitis

\begin{tabular}{|c|c|c|c|c|}
\hline \multirow[t]{2}{*}{ Variables (score range) } & \multicolumn{3}{|c|}{$\begin{array}{l}\text { Age groups in years (mean } \pm \text { SD) } \\
\qquad 42 \pm 11.3\end{array}$} & \multirow[t]{2}{*}{$\begin{array}{c}F \text {-statistic } \\
{ }^{a} p \text {-value }\end{array}$} \\
\hline & $\leq 35$ years & $36-55$ years & $>55$ years & \\
\hline AIS (8-40) & $32.9( \pm 7.8)$ & $25.1( \pm 7.7)$ & $18.4( \pm 8.2)$ & $\begin{aligned} & 15.5 \\
< & 0.0001\end{aligned}$ \\
\hline $\mathrm{BDI}(0-56)$ & $5.4( \pm 5.3)$ & $19.6( \pm 14.0)$ & $34.7( \pm 16.1)$ & $\begin{aligned} & 25.7 \\
&< 0.0001 \\
&\end{aligned}$ \\
\hline SOC (29-203) & $160.6( \pm 25.5)$ & $116.2( \pm 30.1)$ & $87.2( \pm 24.6)$ & $\begin{aligned} & 34.3 \\
< & 0.0001\end{aligned}$ \\
\hline \multicolumn{5}{|l|}{ Components of SOC } \\
\hline Comprehensibility (11-71) & $58.1( \pm 11.7)$ & $43.2( \pm 11.1)$ & $31.4( \pm 6.6)$ & $\begin{aligned} & 28.5 \\
&< 0.0001 \\
&\end{aligned}$ \\
\hline Manageability (17-70) & $57.2( \pm 7.8)$ & $41.0( \pm 11.1)$ & $32.4( \pm 10.6)$ & $\begin{aligned} & 32.8 \\
< & 0.0001\end{aligned}$ \\
\hline Meaningfulness (12-56) & $45.3( \pm 7.1)$ & $32.0( \pm 9.7)$ & $23.5( \pm 9.6)$ & $\begin{aligned} & 30.2 \\
< & 0.0001\end{aligned}$ \\
\hline
\end{tabular}

a Univariate ANOVA for independent groups; AS - ankylosing spondylitis; AIS - Acceptance of IIlness Scale; BDI - Beck Depression Inventory; SOC - Sense of Coherence. 
Table III. Relationship between illness duration and illness acceptance, risk of depression, and sense of coherence of patients with ankylosing spondylitis

\begin{tabular}{|c|c|c|c|c|}
\hline \multirow[t]{2}{*}{ Variables (score range) } & \multicolumn{3}{|c|}{$\begin{array}{l}\text { Disease duration in years (mean } \pm \text { SD) } \\
13 \pm 7.8\end{array}$} & \multirow[t]{2}{*}{$\begin{array}{l}F \text {-statistic } \\
{ }^{a} p \text {-value }\end{array}$} \\
\hline & $\leq 10$ years & $11-20$ years & $>20$ years & \\
\hline AIS (8-40) & $31.7( \pm 7.6)$ & $24.6( \pm 8.5)$ & $21.2( \pm 9.3)$ & $\begin{array}{c}10.1 \\
0.0001\end{array}$ \\
\hline BDI (0-56) & $9.3( \pm 10.8)$ & $20.1( \pm 14.5)$ & $26.3( \pm 18.4)$ & $\begin{array}{c}8.9 \\
0.0003\end{array}$ \\
\hline SOC (29-203) & $145.2( \pm 38.1)$ & $119.0( \pm 30.7)$ & $106.9( \pm 38.1)$ & $\begin{array}{c}7.6 \\
0.0009\end{array}$ \\
\hline \multicolumn{5}{|l|}{ Components of SOC } \\
\hline comprehensibility (11-71) & $52.9( \pm 15.5)$ & $44.7( \pm 10.7)$ & $37.2( \pm 11.9)$ & $\begin{array}{c}7.9 \\
0.0008\end{array}$ \\
\hline manageability (17-70) & $51.5( \pm 12.3)$ & $41.8( \pm 11.8)$ & $39.7( \pm 14.8)$ & $\begin{array}{c}6.7 \\
0.002\end{array}$ \\
\hline meaningfulness (12-56) & $40.8( \pm 11.1)$ & $32.5( \pm 10.2)$ & $29.9( \pm 12.3)$ & $\begin{array}{c}7 \\
0.002\end{array}$ \\
\hline
\end{tabular}

anivariate ANOVA for independent groups; AS - ankylosing spondylitis; AIS - Acceptance of Illness Scale; BDI - Beck Depression Inventory; SOC - Sense of Coherence.

Additionally, a high positive linear correlation between illness acceptance, sense of coherence $\left(r_{p}=0.638\right)$ and SOC components, as well as a very high negative correlation between the overall sense of coherence, the risk of depression $\left(r_{p}=-0.857\right)$ and SOC components, was observed $(p<0.0001)$ (data in Table IV). The lower the risk of depression was, the higher was the sense of coherence (162.4) ( $p<0.0001)$ (data in Table V).

\section{Discussion}

Ankylosing spondylitis, due to its chronic, progressive course and manifestation of major health problems, such as pain, fatigue, limitation of joint mobility, and stiffness, determines the lifestyle of the patients and the attitudes towards the disease. Despite the great advances in the diagnosis and treatment of SpA as well as the existence of biological medications, and their introduction to rheumatology, chronic pain in AS and restriction of movement are still serious problems that decrease patients' quality of life $[4,5]$. As a consequence, worsening of health condition and recurrences of illness lead to a disturbance in the sense of safety, as well as problems with social and psychological functioning. The patients lose control over their life. According to Antonovsky's model of salutogenesis, a patient with a strong sense of coherence, in the face of illness, chooses actions that lead to health within the "health-illness" continuum. Assuming the theoretical salutogenetic perspective indicates the importance of a level of coherence as a dispositional feature; on the one hand, it may be partly related to a chronic illness, and on the other hand, it may or may not help to cope with illness by directing the patient's behavior to pro- or anti-health actions [22].

In the current study, attempts were made to evaluate the functioning of AS patients in the context of adaptation to inflammatory arthritis, their adaptability, ways of perceiving the surrounding reality, and risk of depressive disorders.

Overall, it was demonstrated that patients with AS have an average level of sense of coherence (127.5). Results of SOC measurements performed in Poland in other rheumatic diseases indicated that patients with systemic lupus erythematosus (SLE) had a higher level of coherence (SOC 154) than patients with RA (SOC 117). Both groups of patients have an average level of sense of coherence. Higher SOC among SLE patients was explained by researchers by a higher level of education among patients in this group [16].

In the present study, it was found that people with higher education perceived their situation as significantly better (SOC 155.2) compared to those with primary or secondary education. Analyses have shown that with the education gained, the level of sense of comprehensibility, manageability and meaningfulness increased ( $p<0.0001)$. In the AS group, age was also an important determinant of the overall sense of coherence as well as its particular components $(p<0.0001)$. The younger respondents demonstrated a better perception of reality, the belief in coping with new situations, difficulties, and problem-solving efforts than older people.

Bearing in mind the chronic and progressive course of the disease, which frequently initiates the limitation of social and occupational roles, the disease can be 
Table IV. Analysis of the correlation between age, duration of ankylosing spondylitis, risk of depression, level of illness acceptance and sense of coherence

\begin{tabular}{|c|c|c|c|c|c|c|c|c|c|c|c|c|}
\hline \multirow{3}{*}{\begin{tabular}{|l} 
Variables \\
(score \\
range)
\end{tabular}} & \multirow{2}{*}{\multicolumn{2}{|c|}{ AIS }} & \multirow{2}{*}{\multicolumn{2}{|c|}{$\mathrm{BDI}$}} & \multirow{2}{*}{\multicolumn{2}{|c|}{ SOC }} & \multicolumn{6}{|c|}{ Components of SOC } \\
\hline & & & & & & & \multicolumn{2}{|c|}{ Comprehensibility } & \multicolumn{2}{|c|}{ Manageability } & \multicolumn{2}{|c|}{ Meaningfulness } \\
\hline & ${ }^{\mathrm{b}} r_{p}$ & $p$-value & $r_{p}$ & $p$-value & $r_{p}$ & $p$-value & $r_{p}$ & $p$-value & $r_{p}$ & $p$-value & $r_{p}$ & $p$-value \\
\hline Age & -0.567 & $<0.0001$ & 0.648 & $<0.0001$ & -0.663 & $<0.0001$ & -0.640 & $<0.0001$ & -0.635 & $<0.0001$ & -0.646 & $<0.0001$ \\
\hline $\begin{array}{l}\text { Duration } \\
\text { of diseases }\end{array}$ & -0.446 & $<0.0001$ & 0.479 & $<0.0001$ & -0.448 & $<0.0001$ & -0.453 & $<0.0001$ & -0.396 & 0.0002 & -0.452 & $<0.0001$ \\
\hline AIS & - & - & -0.634 & $<0.0001$ & 0.638 & $<0.0001$ & 0.655 & $<0.0001$ & 0.579 & $<0.0001$ & 0.612 & $<0.0001$ \\
\hline $\mathrm{BDI}$ & -0.634 & $<0.0001$ & - & - & -0.857 & $<0.0001$ & -0.776 & $<0.0001$ & -0.859 & $<0.0001$ & -0.854 & $<0.0001$ \\
\hline
\end{tabular}

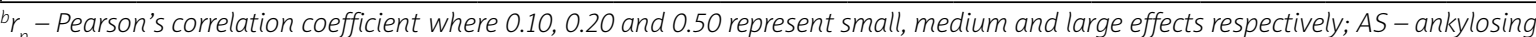
spondylitis; AIS - Acceptance of Illness Scale; BDI - Beck Depression Inventory; SOC - Sense of Coherence.

Table V. Relationship between risk of depression, level of illness acceptance and sense of coherence in patients with ankylosing spondylitis

\begin{tabular}{|c|c|c|c|c|}
\hline \multirow[t]{2}{*}{ Variables (score range) } & \multicolumn{3}{|c|}{$\begin{array}{c}\text { BDI }(0-56)(\text { mean } \pm S D) \\
16.8 \pm 15.3\end{array}$} & \multirow[t]{2}{*}{$\begin{array}{l}\text { F-statistic } \\
\text { ap-value }\end{array}$} \\
\hline & $\begin{array}{l}\text { Lack of depression } \\
\text { or low mood }\end{array}$ & Moderate depression & Severe depression & \\
\hline AIS (8-40) & $31.7( \pm 8.1)$ & $27.1( \pm 6.8)$ & $18.9( \pm 7.7)$ & $\begin{array}{c}19 \\
<0.0001\end{array}$ \\
\hline SOC (29-203) & $162.4( \pm 19.2)$ & $117.7( \pm 17.4)$ & $83( \pm 18.3)$ & $\begin{aligned} & 125.6 \\
< & 0.0001\end{aligned}$ \\
\hline \multicolumn{5}{|l|}{ Components of SOC } \\
\hline comprehensibility (11-71) & $59.3( \pm 8.7)$ & $41.7( \pm 8.3)$ & $32.3( \pm 7.4)$ & $\begin{array}{l}78.8 \\
<0.0001 \\
\end{array}$ \\
\hline manageability (17-70) & $57.2( \pm 6.9)$ & $42.9( \pm 6.9)$ & $29.2( \pm 6.7)$ & $\begin{aligned} & 114.3 \\
< & 0.0001\end{aligned}$ \\
\hline meaningfulness (12-56) & $45.8( \pm 6.1)$ & $33.1( \pm 6.2)$ & $21.5( \pm 5.9)$ & $\begin{array}{c}111 \\
<0.0001\end{array}$ \\
\hline
\end{tabular}

aUnivariate ANOVA for independent groups; AS - ankylosing spondylitis; AIS - Acceptance of Illness Scale; BDI - Beck Depression Inventory; SOC-Sense of Coherence.

a great source of frustration and lead to the depressive spectrum disorder. Consequently the patient may lack the motivation to follow the therapeutic recommendations to combat the disease $[8,23,24]$. At the same time, a literature review shows that after 10 years of disease $10-30 \%$ of patients give up their professional work. The experience of chronic illness usually results in lower self-esteem [25]. Patients may worry about "becoming a burden to their partner" [6].

Our study has shown that a quarter of patients with AS reported risk of severe depression and over $1 / 3$ risk of moderate depression. Disorders from the depressive spectrum intensified with subjects' age and longer duration of AS ( $p<0.05)$, which was confirmed by other studies. AS might increase the risk of a subsequent newly diagnosed depressive disorder, anxiety disorder, or sleep disorder [25-27].

In rheumatic disease such as AS, where there is often a significant degree of physical disability, two problems overlap: the problem of accepting the chronic illness, and the physical disability with usually significant physical deformities [1].

Our study has shown that patients with AS reported average acceptance of disease (AIS 26.9). There was a correlation with age, education and duration of illness.

The analyses conducted by Juczyński [14] among patients with various chronic diseases indicated to what extent the patients accept their limitations imposed by the disease, whether they are self-sufficient, have a high self-esteem and a sense of dependence on others. 
Patients with chronic pain (neuropathy) had the lowest values of AIS (18.46). Patients with spinal pain achieved a mean value of 20.51, and men after myocardial infarction 22.14 [14].

According to Antonovsky's concept, people with a strong sense of coherence more easily avoid risks and dangers, more often treat stressors as a challenge to be tackled, show an instrumental approach to the problem, more willingly and more easily mobilize their immune resources, choose ways of coping with stress appropriate to a given situation, and therefore present a more healthy model of functioning [28].

Analyses have identified that a high level of coherence is manifested by a higher level of acceptance of rheumatic disease and a lower risk of depression. With age and illness duration, the sense of coherence decreased and the risk of depression increased. The low level of illness acceptance also correlated with the sense of coherence of patients with AS.

The impact of ailments on the perception of disease is confirmed by Chumbler's study on patients with chronic musculoskeletal pain. As the level of SOC increased, the risk of depression decreased, and vice versa [29]. Similar results were obtained by Badura-Brzoza et al. [30] in patients after limb amputation and after spinal surgery and Kurowska and Żbikowska [23], who studied patients with degenerative changes in the spine.

Taking into account the above-mentioned theme, the relationship between various factors and the ability to cope with rheumatic disease, there is a need to support those affected by chronic diseases, helping them to adapt to new life situations and cope with difficulties $[5,30]$. In addition to rheumatological care, patients should be provided with specialist psychiatric and psychotherapeutic care.

The patient should have the possibility to learn how to overcome stress (relaxation techniques) as well as how to deal with illness. It is important to build motivation to fight the disease and to work on a positive self-image $[23,24]$. The efforts of health professionals should aim to make patients' lives more active and more like healthy people's everyday life, despite the limitations and difficulties that exist. These activities may make it possible for people with AS to function optimally while having the disease and to perform social roles [6].

\section{Study limitations}

The study on patients with AS has limitations due to the applied research tool questionnaire, based on assessment of their own health, which prevents independent verification of data. Another limitation of the study stems from the fact that it was conducted in a particular part of Poland (Podlasie voivodeship), so the results do not refer to the entire population of Polish patients diagnosed with AS. Participants in the study were those who sought hospital treatment, which could limit the results to only those who are interested in seeking medical care.

\section{Conclusions}

In interdisciplinary therapeutic interventions aimed at improving the adaptation of patients with AS to living with SpA and coping with difficulties, socio-demographic factors such as older age and lower education should be taken into consideration as they are associated with lower coherence, poorer acceptance of the disease, and a greater risk of depression.

An important determinant of the intensification of emotional problems, lower self-esteem, sense of dependence on others and worse inner balance (coherence) of the studied patients was chronic AS.

\section{Acknowledgements}

The authors thank the cooperating institution (Department of Rheumatology and Internal Diseases of the Medical University of Białystok) and participants.

This work has been financially supported by Medical University of Biatystok, Poland.

The authors declare no conflict of interest.

\section{References}

1. Dobrucka-Janeczek I, Jędryka-Góral A. Problemy psychologiczne w chorobach reumatycznych. Post Nauk Med 2012; 2: 152-155.

2. Hamilton-West KE, Quine L. Living with Ankylosing Spondylitis: the patient's perspective. J Health Psychol 2009; 14: 820-830.

3. Dean LE, Jones GT, MacDonald AG, et al. Global prevalence of ankylosing spondylitis. Rheumatology (Oxford) 2014; 53: 650-657.

4. Wiland P, Filipowicz-Sosnowska A, Głuszko P, et al. The Expert Panel of the National Consultant for Rheumatology recommendations for the management of ankylosing spondylitis. Reumatologia 2008; 46: 191-197.

5. Sierakowska M, Rudzik T. Opieka pielęgniarska nad osobami z chorobami reumatycznymi. In: Pielęgniarstwo Internistyczne, Talarska D, Zozulińska-Ziółkiewicz D (eds.). Wyd. Lekarskie PZWL, Warszawa 2017: 335-373.

6. Hamilton-West K. Managing the impact of ankylosing spondylitis on the patient and society. Int J Clin Rheumatol 2010; 5 : 537-546.

7. Antonovsky A. Unraveling the mystery of health: How people of manage stress and stay well. Jossey-Bass, San Francisco 1987.

8. Eriksson M, Lindström B. Antonovsky's sense of coherence scale and its relations with quality of life: systematic review. J Epidemiol Community Health 2007; 61: 938-944. 
9. Olsson M, Hansson K, Lundblad AM, Cederblad M. Sense of coherence: definition and explanation. Int J Soc Welf 2006; 15 219-229.

10. Antonovsky A. Solving the mystery of health. How to deal with stress and not get sick. Fundacja IPN, Warszawa 1995.

11. Ostrzyżek A. Jakość życia w chorobach przewlekłych. Probl Hig 2008; 89: 467-470.

12. Beck AT. A systematic investigation of depression. Compr Psychiatry $1961 ; 2: 163-170$.

13. Felton BJ, Revenson TA, Hinrichsen GA. Stress and coping in the explanation of psychological adjustment among chronically ill adults. Soc Sci Med 1984; 18: 889-898.

14. Juczyński Z. Measurement tools in the health psychology. Clin Psychol Rev 1999; 42: 43-56.

15. Antonovsky A. The structure and properties of Sense of Coherence Scale. Soc Sci Med 1993; 36: 725-733.

16. Kurowska K, Żegarska K, Głowacka M, et al. Sense of coherence in patients with rheumatic disorders. Psychogeriatr Pol 2009; 6: 9-14.

17. Koniarek J, Dudek B, Makowska Z. Sense of Coherence Questionnaire. Adaptation the Sense of Coherence Questionnaire (SOC) A. Antonovsky'ego. Przegl Psychol 1993; 36: 491-502.

18. Beck AT, Steer RA, Brown GK. BDI-II. Beck Depression Inventory. Manual. The Psychological Corporation, San Antonio 1996.

19. Morley S, Williams A, Black S. A confirmatory factor analysis of the Beck Depression Inventory in chronic pain. Pain 1999, 1-2: 289-298.

20. Parnowski T, Jernajczyk W. Inwentarz Depresji Becka w ocenie nastroju osób zdrowych i chorych na choroby afektywne. Psychiatr Pol 1997; 11: 417-421.

21.Zawadzki B, Popiel A, Pragłowska E. Psychometric Properties of the Polish Version of the Aaron T. Beck's Depression Inventory BDI-II. Psychol Etol Genet 2009; 19: 71-95.
22. Sęk H. Orientacja patogenetyczna i salutogenetyczna w psychologii klinicznej. In: Psychologia kliniczna, Sęk H (ed.), t. I. Wydawnictwo Naukowe PWN, Warszawa 2013: 40-54.

23. Kurowska K, Żbikowska A. Depresyjność a poczucie koherencji u pacjentów ze zmianami zwyrodnieniowymi kręgosłupa. Nowiny Lekarskie 2011; 80: 441-446.

24. Esen SA, Esen I, Karabulut Y, Atmis V. Effects of the disease characteristics and the treatment on psychological status in patients with rheumatoid arthritis and ankylosing spondylitis. Curr Rheumatol Rev 2018; 14: 271-278.

25. Kulikowski K. Psychologiczny i medyczny kontekst jakości życia osób z chorobami reumatycznymi. Reumatologia 2014; 52: 200-206.

26. Cheng-Che Shen CC, Hu LY, Yang AC, et al. Risk of Psychiatric Disorders following Ankylosing Spondylitis: A Nationwide Population-based Retrospective Cohort Study. J Rheumatol 2016; 43: 625-631.

27. Meesters JJL, Bremander A, Bergman S, et al. The risk for depression in patients with ankylosing spondylitis: a population-based cohort study. Arthritis Res Ther 2014; 16: 418.

28. Salmon P. Chronic illness, dying, mourning. In: Psychology in medicine supports the cooperation with the patient and the treatment process, ed. Salmon P. Gdańskie Wydawnictwo Psychologiczne, Gdańsk 2002: 110-117.

29. Chumbler NR, Kroenke K, Outcalt S, et al. Association between sense of coherence and health-related quality of life among primary care patients with chronic musculoskeletal pain. Health Qual Life Out 2013; 11: 216.

30. Badura-Brzoza K, Matysiakiewicz J, Piegza M, et al. Sense of coherence in patients after limb amputation and in patients after spine surgery. Int J Psychiat Clin 2008; 12: 41-47. 